\title{
Correction to: Correlates of olfactory impairment in middle-aged non-diabetic Caucasian subjects with stage I-Il obesity
}

\author{
Jonica Campolo ${ }^{1}$ - Ettore Corradi ${ }^{2} \cdot$ Alice Rizzardi $^{1} \cdot$ Marina Parolini $^{1} \cdot$ Cinzia Dellanoce $^{1}$. \\ Maria Luisa Di Guglielmo ${ }^{1}$ Patrizia Tarlarini ${ }^{2} \cdot$ Marina Cattaneo $^{2} \cdot$ Maria Giovanna Trivella $^{1} \cdot$ Renata De Maria ${ }^{1}$
}

Published online: 21 January 2021

○) Springer-Verlag GmbH Germany, part of Springer Nature 2021

\section{Correction to: European Archives of Oto-Rhino-Laryngology https://doi.org/10.1007/s00405-020-06442-5}

In the original publication of the article, the acknowledgment section was not included and provided below in this correction.

Acknowledgement We acknowledge the skillful secretarial assistance and patients flow management provided by Elisabetta Spagnolo.

The original article has been updated.
Publisher's Note Springer Nature remains neutral with regard to jurisdictional claims in published maps and institutional affiliations.

The original article can be found online at https://doi.org/10.1007/ s00405-020-06442-5.

Renata De Maria

renata.demaria@ospedaleniguarda.it

1 CNR Institute of Clinical Physiology, ASST Grande

Ospedale Metropolitano Niguarda, Milan, Italy

2 Clinical Nutritional Unit, ASST Grande Ospedale Metropolitano Niguarda, Milan, Italy 